\title{
Sublingual plus oral midazolam without intravenous access to complement topical anesthesia for phacoemulsification
} surgery

\author{
Nathaniel Gelinas ${ }^{1}$, Thomas Silbernagel ${ }^{2}$, Terrence McCanna ${ }^{3}$ and Thomas Harvey ${ }^{3 *}$ \\ ${ }^{1}$ Midwestern University, USA \\ ${ }^{2}$ Memorial Medical Center, USA \\ ${ }^{3}$ Chippewa Valley Eye Clinic, USA
}

\begin{abstract}
Purpose: To evaluate sublingual/oral midazolam in phacoemulsification patients with no intravenous line. Design: prospective, consecutive case series as part of a quality assurance program.

Methods: Two surgeons' data from 193 consecutive procedures receiving sublingual plus oral midazolam were analyzed for total midazolam dose, need for additional medications, nausea/vomiting, respiratory depression, and total monitoring time. Low health-risk (American Society of Anesthesiologist 2 (ASA2) and higher health-risk (American Society of Anesthesiologist 3(ASA3)) groups were compared.

Results: There were no statistical differences between groups, except ASA2 cases required more midazolam syrup than ASA3 cases $(5.94 \pm 0.18$ vs. $5.08 \pm 0.08$ mg, $\mathrm{p}<0.001)$. Fewer than $3 \%$ of all cases needed additional medication or experienced nausea. Average time monitored was under 80 minutes. One patient had mild (successfully treated) respiratory depression. Only 3 cases required additional syrup, and only 3 intravenous lines were started. There were no intraoperative events.

Conclusion: Sublingual/oral midazolam without intravenous line is a safe, efficient complement to topical anaesthesia for phacoemulsification with IOL.
\end{abstract}

\section{Precis}

Sublingual/oral midazolam without intravenous line is a safe, efficient means of achieving monitored anaesthesia care for phacoemulsification with IOL that offers advantages to both patient and surgeon.

\section{Introduction}

For nearly two decades, topical anesthesia has been used for phacoemulsification with intraocular lens (IOL) placement. The addition of systemic sedation to topical anesthesia has become the standard of care at most institutions. Traditionally, intravenous(IV) agents have been used to achieve appropriate sedation to create an optimal operating environment for both patient and surgeon [1-3].

While a peripheral intravenous line provides immediate access to the venous circulation, there are downsides to its use in topical phacoemulsification. Pain on placement/drug administration, ecchymosis, infiltration, and thrombophlebitis are some disadvantages. Some patients suffer through difficult intravenous line placement for a variety of reasons including obesity, low intravascular volume, and scarring from previous venipuncture. Surgical delay can result from these situations as well as decreased patient satisfaction and comfort. The ideal sedative should be easily administered with little patient discomfort and produce a reliable level of sedation, highlighting the need to consider other options to obtain intraoperative sedation in phacoemulsification surgery [4-5].
Sublingual and oral administration of benzodiazepines prior to surgery can avoid these problems while still achieving satisfactory sedation. The oral mucosa provides a direct route to venous circulation via the sublingual veins (Figure 1), while avoiding the need for intravascular devices. Midazolam, due to its short half-life, allows for rapid onset of sedation and quick post-operative recovery [6-10]. We describe herein the use of midazolam via combined sublingual and oral routes without an intravenous line for routine topical phacoemulsification with IOL.

\section{Methods}

Of the first 200 topical anesthesia, anterior segment cases in a new freestanding surgery center, 193 were included in this study. Only patients undergoing phacoemulsification with IOL were included; the seven patients excluded had other procedures performed. The analysis was undertaken as part of a government-mandated quality assurance program. Data collection was performed in accordance with the Health Insurance Portability and Accountability Act (HIPPA). This study was conducted at a private, freestanding surgery center with no formal IRB board, so no formal IRB approval was required. All standard principals of ethics in research regarding human medicine were strictly followed.

Correspondence to: Thomas Harvey, MD, 2715 Damon St Eau Claire, WI 54701, USA; Tel: (715) 797-8320; E-mail: tharvey@cv-eye.com

Received: February 15, 2017; Accepted: March 24, 2017; Published: March 28, 2017 


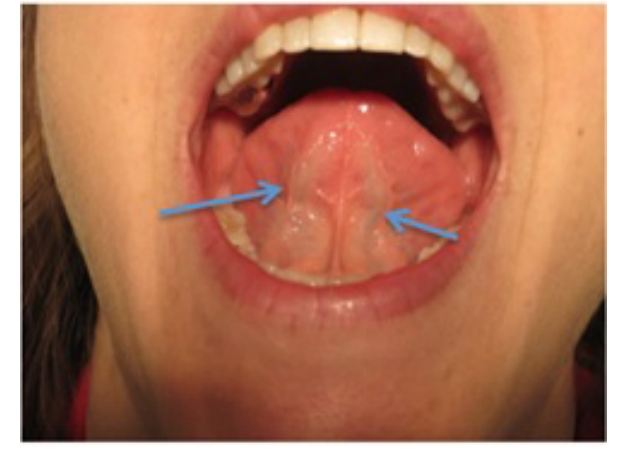

Figure 1. High definition image of the sublingual veins, as indicated by arrows. Midazolam contact is maximized with upright positioning of the patient and avoids inadvertent early swallowing of the medication.

Patients were positioned upright and given cherry-flavored sublingual midazolam syrup (with pulse oximetry and blood pressure monitoring) approximately 20 minutes prior to surgery. Initial midazolam dose was determined by a certified nurse anesthetists and was typically between 2 and $8 \mathrm{mg} / \mathrm{mL}$. After four minutes, patients were instructed to swallow the remaining syrup.

Each case was performed by one of two surgeons (TH, TM) in standard fashion, using topical anesthetics, clear cornea incisions, as needed intracameral lidocaine $1 \%$ (preservative free), and phacoemulsification with foldable IOL placement. A certified registered nurse anesthetist carried out intraoperative monitoring, including electrocardiogram.

Cases were divided into two groups (ASA2 or ASA3) according to each patient's American Society of Anesthesiology (ASA) status. Patients that had both eyes treated (usually two weeks apart) were considered separately for purposes of analysis. Endpoints were midazolam syrup dosage, additional medication requirement, presence of nausea/vomiting post operatively, and observation time. Observation time was defined as the time from administration of midazolam syrup to the final vital check prior to discharge from the recovery area. Additionally, events including respiratory depression, the need for a second dosing of midazolam syrup, and need for IV line placement were recorded. Respiratory depression was defined as fewer than 12 breaths per minute at any time that vitals were recorded. Vitals were recorded preoperatively, during surgery and postoperatively.

Statistical analysis was carried out using the open-source system for statistical computation, R-2.15.3 [11]. Analyses of the primary endpoints used a two-sample t-test comparing the ASA2 group to the ASA3 group. P-values presented are the nominal unadjusted values derived from the two-sided t-test unless otherwise noted. A two-sided t-test with a $P$ value $\leq 0.05$ was considered statistically significant.

\section{Results}

Table 1 summarizes the study findings. Of the 193 topical phacoemulsification/IOL cases, 70 were women and 54 were men (totaling 124 patients). There were 34 patients in the low health risk (ASA2) cohort, while there were 90 patients designated as ASA3. Mean sublingual plus oral midazolam dose for the ASA 2 group (5.94 mg) was significantly greater $(\mathrm{p}<0.001)$ than the mean dose for ASA $3(5.08 \mathrm{mg})$ group. Also reaching significance, ASA3 patients were older (mean age 73.1 years) by approximately a decade than for ASA2 (mean age 64.4 years). All other inter-group differences did not reach statistical significance. Approximately $9 \%$ of patients in the ASA2 group and
$1 \%$ of patient in ASA3 group required additional midazolam syrup after initial dosing for improved anxiolytics. Mean observation time was less 90 minutes for both groups. Three patients within the ASA3 group required an intraoperative intravenous access compared to zero patients within the ASA 2 group. One patient within the ASA 2 group required additional sedative medication while three patients within the ASA 3 group required additional sedative medication. Three patients within the ASA2 group experienced nausea/vomiting while one patient within the ASA3 group experienced nausea/vomiting. There were no unexpected intraoperative events, aborted surgeries, or medical emergencies

\section{Discussion}

Monitored anesthesia care for topical phacoemulsification surgery does not necessitate an intravenous line. This study endorses a combined sublingual/oral midazolam technique without an IV for multiple reasons, including: 1) sedation prior to entering the operative suite, 2) moderately rapid onset of action, 3) lack of complications associated with intravenous access and 4) efficacy without hassle. Sublingual midazolam produces a moderately rapid and predictable onset of sedation. Sedation provided is deep enough to provide an optimal environment for phacoemulsification surgery, but still allows communication between patients and surgeon if required [12]. As noted in the introduction, eliminating preoperative needle sticks has strong benefits for both patient and surgeon.

The results of this study strongly support that sublingual midazolam is an efficacious and safe means of sedation for phacoemulsification surgery. Fewer than $3 \%$ of all cases required additional medication or experienced nausea/vomiting. Average time monitored was under 80 minutes. One patient had mild (successfully treated) respiratory depression. Only 3 cases required additional syrup, and only 3 intravenous lines were started. There were no intraoperative events. This study's data suggests undesirable events with this approach are both uncommon and manageable.

This studies results also supports that sublingual midazolam is equally viable among the wide range of health states of individuals whom undergo phacoemulsification surgery. Of the endpoints recorded, when comparing ASA 2 and ASA3 cohorts, only average dosage showed significant differences $(\mathrm{p}<0.05)$. Average dosage required for adequate sedation was significantly greater in the ASA2 cohort compared to the ASA3 cohort. The reason for this statistical difference is unclear but may be related to the older age of ASA3 patients.

Resistance to this option may come from surgeons that desire deep sedation and from anesthesia staff that require full-time intravenous access. However, Sharwood et al. [13] studied 693 patients undergoing phacoemulsification surgery and reported only $1 \%$ of cases required intraoperative anesthesiologist intervention. If necessary, in the rare case of complications requiring intravenous pharmacological care, intravenous access by skilled anesthesia staff can be gained expediently.

Since the completion of this quality assurance study, we have completed more than 3000 sublingual/oral midazolam surgeries in this center with the same technique. There have been no medical emergencies or undesirable outcomes related to anesthesia. Although this was not a satisfaction study, patients, nurses, and surgeons seem to favor this approach over intravenous delivery. In fact, our anesthesia team has taken this technique to neighboring facilities in which they work.

In the United States, there have been recent shortages of medications used for intravenous-delivered MAC anesthesia. This 
Table 1. Results.

\begin{tabular}{|c|c|c|c|c|c|c|c|c|}
\hline & $\begin{array}{c}\text { Age } \\
(95 \% \mathrm{CI})\end{array}$ & $\begin{array}{l}\text { Gender (M:F) } \\
\text { (as persons) }\end{array}$ & $\begin{array}{l}\text { Average Dose } \\
(\mathrm{mg} / \mathrm{mL} ; 95 \% \mathrm{CI})\end{array}$ & Additional Syrup ${ }^{a}$ & $\begin{array}{c}\text { Other Medication } \\
(\mathrm{Y}: \mathrm{N})\end{array}$ & $\begin{array}{c}\text { Nausea, Vomiting } \\
\text { (Y:N) }\end{array}$ & IV Placed (Y:N) & $\begin{array}{c}\text { Observation Time } \\
(95 \% \mathrm{CI})\end{array}$ \\
\hline $\begin{array}{l}\text { ASA2 } \\
(\mathrm{N}=34)\end{array}$ & $\begin{array}{c}64.4 \\
(61.3-67.5)\end{array}$ & $16: 18$ & $\begin{array}{c}5.94 \\
(5.60-6.29)\end{array}$ & $\begin{array}{c}0.09 \\
(0.01-0.17)\end{array}$ & $1: 53$ & $3: 51$ & $0: 54$ & $\begin{array}{c}76.0 \\
(71.0-81.3)\end{array}$ \\
\hline $\begin{array}{l}\text { ASA3 } \\
(\mathrm{N}=90)\end{array}$ & $\begin{array}{c}73.1 \\
(71.2-75.1)\end{array}$ & $38: 52$ & $\begin{array}{c}5.08 \\
(4.86-5.30)\end{array}$ & $\begin{array}{c}0.01 \\
(0-0.06)\end{array}$ & $3: 136$ & $1: 138$ & $3: 136$ & $\begin{array}{c}79.0 \\
(75.7-82.4)\end{array}$ \\
\hline$P$ value & $<0.001$ & 0.78 & $<0.001$ & 0.10 & $>0.99$ & 0.12 & 0.56 & 0.33 \\
\hline
\end{tabular}

${ }^{a}$ Three cases total required extra Syrup.

${ }^{\mathrm{b}}$ Analyzed as $\log$ (Observation Time).

is under investigation, but recent difficulty in obtaining injectable midazolam, diprivan, and fentanyl/derivatives has necessitated use of alternative methods. The etiology of this problem is multifactorial and systemic. It is likely to continue and reoccur into the foreseeable future [14-16]. Midazolam syrup has not been in shortage status, making this inexpensive option even more appealing. Centers that wish to start this technique can initially use a capped IV as a backup to gain confidence in consistency of sedation.

This study is not without weaknesses. The ASA cohorts were not equal in size. Both groups would have to be much larger (around 200 cases per group) to determine intergroup differences in observation time. Some patients had both eyes treated, which could create bias. We did not analyze blood pressure, pulse rate, or pain. The study design did not include any intravenous-delivery control. Therefore, no superiority claim is made.

Cataract surgery is a highly successful, cost effective surgery [1719]. While not every patient or facility may be appropriate for this approach, we strongly support combined sublingual/oral midazolam sedation as an effective adjunct to continue to optimize topical phacoemulsification surgery.

\section{Conflict of Interest}

Presented at the American Society of Cataract and Refractive Surgery Symposium, San Francisco, USA, 2013.

The authors of this paper have no proprietary or monetary interests to disclose regarding any of the following materials or methods presented in this manuscript.

\section{References}

1. Novak KD, Koch DD (1995) Topical anesthesia for phacoemulsification: initial 20case series with one month follow-up. J Cataract Refract Surg 21: 672-675. [Crossref]

2. Habib NE, Mandour NM, Balmer HG (2004) Effect of midazolam on anxiety level and pain perception in cataract surgery with topical anesthesia. J Cataract Refract Surg 30: 437-443. [Crossref]

3. Shafquat S, Dhileepan S, Child C, Horgan S (2001) Sedation for cataract surgery. $J$ Cataract Refract Surg 27: 176. [Crossref]
4. Kagel EM, Rayan GM (2004) Intravenous catheter complications in the hand and forearm. J Trauma 56: 123-127. [Crossref]

5. Campbell L (1998) I.v.-related phlebitis, complications and length of hospital stay: 1 Br J Nurs 7: 1304-1306, 1308-12. [Crossref]

6. Harman DM (2000) Combined sedation and topical anesthesia for cataract surgery. $J$ Cataract Refract Surg 26: 109-113. [Crossref]

7. Mönestam E, Kuusik M, Wachtmeister L (2001) Topical anesthesia for cataract surgery: a population-based perspective. J Cataract Refract Surg 27: 445-451. [Crossref]

8. Bellan L, Gooi A, Rehsia S (2002) The Misericordia Health Centre cataract comfort study. Can J Ophthalmol 37: 155-160. [Crossref]

9. Pang MP, Wilkens LR, On SJ, McMullin B (2004) Oral sedation for cataract surgery. $J$ Cataract Refract Surg 30: 1810-1812. [Crossref]

10. Rocha G, Turner C (2007) Safety of cataract surgery under topical anesthesia with oral sedation without anesthetic monitoring. Can J Ophthalmol 42: 288-294. [Crossref]

11. Dean CB, Nielsen JD (2007) Generalized linear mixed models: a review and some extensions. Lifetime Data Anal 13: 497-512. [Crossref]

12. Lim TW, Thomas E, Choo SM (1997) Premedication with midazolam is more effective by the sublingual than oral route. Can J Anaesth 44: 723-726. [Crossref]

13. Sharwood PL, Thomas D, Roberts TV (2008) Adverse medical events associated with cataract surgery performed under topical anaesthesia. Clin Exp Ophthalmol 36: 842846. [Crossref]

14. Mazer-Amirshahi M, Pourmand A, Singer S, Pines JM, Anker J, et al. (2014) Critica Drug Shortages: Implications for Emergency Medicine. Acad Emerg Med 21: 704-711. [Crossref]

15. Goldsack JC, Reilly C, Bush C, McElligott S, Bristol MN, et al. (2014) Impact of shortages of injectable oncology drugs on patient care. Am J Health Syst Pharm 71: 571-578. [Crossref]

16. Kweder SL, Dill S (2013) Drug shortages: the cycle of quantity and quality. Clin Pharmacol Ther 93: 245-251. [Crossref]

17. Busbee BG, Brown MM, Brown GC, Sharma S (2002) Incremental cost-effectiveness of initial cataract surgery. Ophthalmology 109: 606-612. [Crossref]

18. McCarty CA, Nanjan MB, Taylor HR (2001) Vision impairment predicts 5 year mortality. Br J Ophthalmol 85: 322-326. [Crossref]

19. Wang JJ, Mitchell P, Simpson JM, Cumming RG, Smith W (2001) Visual impairment, age-related cataract, and mortality. Arch Ophthalmol 119: 1186-1190. [Crossref]

Copyright: (C2017 Gelinas N. This is an open-access article distributed under the terms of the Creative Commons Attribution License, which permits unrestricted use, distribution, and reproduction in any medium, provided the original author and source are credited. 